\title{
Movimento de água e resistência à penetração em um Latossolo Vermelho distrófico de cerrado, sob diferentes usos e manejos ${ }^{1}$
}

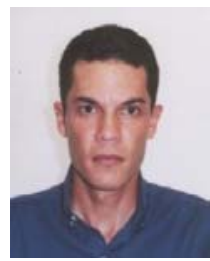

Zigomar M. de Souza² \& Marlene C. Alves ${ }^{3}$

\author{
1 Parte da dissertação de Mestrado do primeiro autor, apresentada a UNESP, Campus de Ilha Solteira, SP, financiado \\ pela FAPESP \\ 2 FEIS/UNESP. CP 31, CEP 15385-000, Ilha Solteira, SP. E-mail: zigomar@fcav.unesp.br (Foto) \\ ${ }^{3}$ FEIS/UNESP. CP 31, CEP 15385-000, Ilha Solteira, SP. E-mail: mcalves@agr.feis.unesp.br
}

Protocolo $108-1 / 8 / 2002$ - Aprovado em 24/2/2003

\begin{abstract}
Resumo: Na Fazenda Experimental da Faculdade de Engenharia de llha Solteira - UNESP, no Estado do Mato Grosso do Sul, conduziu-se um estudo com o objetivo de se avaliar as modificações do movimento de água de um Latossolo Vermelho distrófico sob vegetação de cerrado, para diferentes condições de uso e manejo do solo. $O$ delineamento experimental foi inteiramente casualizado, com 6 tratamentos e 10 repetições, constando dos seguintes usos e manejos: plantio direto com culturas anuais; preparo convencional com culturas anuais; cultivo mínimo com culturas anuais; vegetação natural (cerrado); área com pastagem e área com cultura de seringueira. Foram avaliados o movimento da água no solo através da infiltração na superfície, condutividade hidráulica do solo saturado e resistência do solo à penetração, nas profundidades de $0-0,10 ; 0,10-0,20$ e 0,20-0,40 m. O uso e o manejo do solo alteraram o movimento da água do solo e sua resistência à penetração. $\mathrm{O}$ cultivo mínimo revelou-se como o sistema de manejo com melhores resultados, mostrando maior capacidade de infiltração de água no solo, condutividade hidráulica do solo saturado e menor resistência do solo à penetração, quando comparado ao sistema de vegetação natural. Dentre os sistemas de usos e manejos estudados, os sistemas com seringueira e pastagem apresentaram menor capacidade de infiltração da água no solo e maior resistência do solo à penetração.
\end{abstract}

Palavras-chave: manejo do solo, condutividade hidráulica do solo saturado, infiltração de água no solo

\section{Water movement and resistence to penetration in a distrophic Red Latosol of cerrado under different uses and management}

\begin{abstract}
This study was conducted at Experimental Station of Faculdade de Engenharia - UNESP, Ilha Solteira County, in Mato Grosso do Sul State, Brazil. The aim was to evaluate the water movement modifications of a Red Latosol under cerrado submited to different uses and managements. A completely randomized design with 6 treatments and 10 replicates was adopted. The treatments used and managements were: no-tillage with annual crops, conventional tillage with annual crops, minimum tillage with annual crops, native vegetation (cerrado), pasture and rubber crop. The water movement was measured through water infiltration in soil, hydraulic conductivity of saturated soil and soil resistence to penetration at $0-0.10 ; 0.10-0.20$ and 0.20 $0.40 \mathrm{~m}$ depth. The results showed that soil use and management changed the water movement and soil resistence to penetration. The minimum tillage was the best management system providing higher soil water infiltration capacity, saturated hydraulic conductivity and the lower soil resistence to penetration when compared to the native vegetation system. Among different uses and management, the systems with rubber crop and pasture showed the lower water movement in soil and higher soil resistence to penetration in relation to the native vegetation system.
\end{abstract}

Key words: soil management, hydraulic conductivity of saturated soil, water infiltration in soil

\section{INTRODUÇÃO}

A região dos cerrados ocupa $24 \%$ da área do território brasileiro, tornando-se importante na produção de grãos com a expansão da fronteira agrícola. De modo geral, os sistemas de preparo nesta região se caracterizam pelo alto grau de revolvimento do solo, por meio do uso da grade aradora e arado de discos, que acarretam impactos negativos nos atributos físicos 
do solo, comprometendo a sustentabilidade ambiental (Silveira et al., 1997; Correchel et al., 1999).

Os diferentes sistemas de manejo de solos têm a finalidade de criar condições favoráveis ao desenvolvimento das culturas. Todavia, o desrespeito às condições mais favoráveis (solo úmido - consistência friável) para o preparo do solo e o uso de máquinas cada vez maiores e pesadas para essas operações podem levar a modificações na estrutura do solo, causando-lhe maior ou menor compactação, que poderá interferir na infiltração de água no solo, na condutividade hidráulica do solo saturado e no desenvolvimento radicular das culturas e, conseqüentemente, reduzir sua produtividade (Derpsch et al., 1991; Tavares Filho \& Tessier, 1998; De Maria et al., 1999).

A permeabilidade do solo depende, dentre outros fatores, da quantidade, da continuidade e do tamanho de poros, sendo a compactação e a descontinuidade dos poros responsáveis pela redução significativa da permeabilidade do solo à água. $\mathrm{O}$ conhecimento da velocidade de infiltração da água no solo e da condutividade hidráulica são fundamentais para a solução de problemas relativos às áreas de irrigação, drenagem, conservação da água e do solo e controle do deflúvio superficial, sendo de grande importância para o manejo do solo e da água, o entendimento do processo de infiltração e de suas relações com as propriedades do solo.

Quando um solo começa a ser cultivado há alterações na sua estrutura natural. Lal (1974) verificou redução de 40 e 73\% na infiltração acumulada, numa área cultivada com milho por um ano, e em outra preparada e sem cobertura, no mesmo período, respectivamente, comparadas com uma área sob floresta. Segundo o autor, as diferenças foram devidas às alterações na estrutura, sobretudo na superfície; a energia cinética das gotas de chuva é responsável por essas alterações, causando o selamento, que reduz a infiltração acumulada e a taxa de infiltração. Na tentativa de solucionar os problemas decorrentes do preparo convencional, surgiram os preparos conservacionistas, que proporcionam menor mobilização do solo e mantêm maior proteção da superfície com os resíduos culturais. O plantio direto e o cultivo mínimo são tipos de preparo conservacionista que procuram minimizar a mobilização do solo.

As alterações que ocorrem na estrutura do solo, evidenciando-se por modificações nos valores de densidade do solo, afetam sua resistência à penetração, a porosidade total, a distribuição do diâmetro dos poros e sua porosidade de aeração, a armazenagem e disponibilidade de água às plantas, a dinâmica da água na superfície e no seu perfil, bem como a consistência e a máxima compactabilidade do solo (Klein et al., 1998). A resistência do solo à penetração aumenta com a compactação do solo, sendo restritiva ao crescimento radicular acima de certos valores de potencial que variam de 1,5 a 3,0 $\mathrm{MPa}$, conforme Grant \& Lafond (1993); e de 2,0 a 4,0 MPa, segundo Arshad et al. (1996), sendo admitidos valores superiores em plantio direto, na ordem de 5,0 MPa, observados por Ehlers et al. (1983).

Considerando-se a influência dos diferentes tipos de uso e manejo sobre as propriedades do solo, o presente trabalho objetivou avaliar as modificações do movimento de água de um Latossolo Vermelho distrófico de cerrado, sob diferentes usos e manejos.

\section{MATERIAL E MÉTODOS}

O estudo foi conduzido na Fazenda de Ensino e Pesquisa da Faculdade de Engenharia, Campus de Ilha Solteira, da Univer- sidade Estadual Paulista "Júlio de Mesquita Filho", situada na margem direita do Rio Paraná, no município de Selvíria, MS, localizada nas coordenadas $20^{\circ} 22^{\prime} \mathrm{S}$ e $51^{\circ} 22^{\prime} \mathrm{W}$. O tipo climático, segundo Köppen, é Aw, caracterizado como tropical úmido com estação chuvosa no verão e seca no inverno, estando a umidade relativa dos meses mais chuvosos entre 60 e $80 \%$. A vegetação original encontrada na área foi descrita como sendo do tipo cerrado e o solo da área em estudo foi previamente classificado como Latossolo Vermelho-Escuro álico, textura argilosa (Demattê, 1980). Por meio do levantamento detalhado efetuado por Demattê (1980), assim como se utilizando o Sistema Brasileiro de Classificação de Solos (EMBRAPA, 1999), o solo utilizado no presente trabalho foi um Latossolo Vermelho distrófico típico argiloso, A moderado, hipodistrófico, álico, caulinítico, férrico, compactado, muito profundo e moderada-mente ácido (LVd).

Os tratamentos estudados foram: 1. cerrado (vegetação natural); 2. cultivo mínimo - escarificação e gradagem leve (culturas anuais); 3. pastagem (Brachiaria decumbens); 4. preparo convencional - gradagem pesada (aradora) e gradagem leve (niveladora) - (culturas anuais); 5. plantio direto (culturas anuais); e 6. área com seringueira (Hevea brasiliensis Muell Arg.). As áreas com plantio direto e cultivo mínimo estão sendo utilizadas com esses sistemas de preparo há oito anos. O preparo convencional e a seringueira apresentam 16 anos de uso e a pastagem tem 20 anos de instalação. O tamanho de cada área de estudo foi de 1 ha, sendo que a condutividade hidráulica do solo saturado e a resistência do solo à penetração foram avaliadas em três profundidades (0-0,10; 0,10-0,20 e 0,20-0,40 m).

A área com vegetação natural onde predominam as formas arbustivas em solo profundo, pouco fértil, conhecida como cerrado, foi desmatada em 1978, sendo que em 1990 se implantou o sistema convencional, plantio direto e cultivo mínimo. Os sistemas de plantio direto e cultivo mínimo apresentam uma seqüência de culturas com leguminosas e gramíneas como feijão (Phaseolus vulgaris), milho (Zea mays L.), soja (Glycine Max (L) Merril) e aveia preta (Avena strigosa Schieb); o manejo de plantas invasoras tem sido efetuado com herbicidas. Efetuouse a calagem antes da implantação dos sistemas plantio direto, cultivo mínimo e preparo convencional, com o objetivo de elevar a saturação por bases a $60 \%$. As culturas de feijão, milho e soja, receberam uma adubação anual de $200 \mathrm{~kg} \mathrm{ha}^{-1}$ da fórmula 4-3010. As áreas de pastagem (Brachiaria decumbens) e seringueira só receberam calagem e adubação na sua implantação.

Para cada área em estudo, realizaram-se as seguintes determinações: a) infiltração de água no solo - taxa constante de infiltração e a infiltração acumulada foram determinadas mediante o emprego de anéis concêntricos (Bertrand, 1965) em outubro e novembro de 1999. O modelo matemático empregado para descrever a infiltração acumulada foi a equação de Kostiakov (1932), dada por:

$$
\begin{gathered}
i(t)=\alpha t^{-\beta} \\
I(t)=\frac{\alpha}{1-\beta} t^{(1-\beta)} \quad \alpha>0 \text { e }(0<\beta<1)
\end{gathered}
$$

em que: $\alpha$ e $\beta$ são constantes empíricas e t tempo (h). A equação de Kostiakov descreve com maior precisão a infiltração de água no solo para valores pequenos de tempo, sendo menos precisa 
para valores elevados de tempo; b) condutividade hidráulica do solo saturado no campo - foram feitas as medições nos meses de setembro e outubro de 1999. Para esta avaliação, empregouse o permeâmetro de Guelph, modificado por Vieira (1996) cujo funcionamento é baseado no princípio de Mariotte. Mediu-se a taxa constante de infiltração e se calculou a condutividade hidráulica do solo saturado no campo (Kfs) segundo Reynolds \& Elrick (1985). Feitas as medições, os dados foram analisados segundo modelos matemáticos propostos por Vieira et al. (1988) que resolveram as seguintes equações:

$$
\begin{aligned}
& \mathrm{Q}_{1}=\left(\frac{2 \pi \mathrm{H}_{1}^{2}}{\mathrm{C}_{1}}+\pi \mathrm{a}^{2}\right) \mathrm{Kfs}+\left(\frac{2 \pi \mathrm{H}_{1}}{\mathrm{C}_{1}}\right) \phi_{\mathrm{m}} \\
& \mathrm{Q}_{2}=\left(\frac{2 \pi \mathrm{H}_{2}^{2}}{\mathrm{C}_{2}}+\pi \mathrm{a}^{2}\right) \mathrm{Kfs}+\left(\frac{2 \pi \mathrm{H}_{2}}{\mathrm{C}_{2}}\right) \phi_{\mathrm{m}}
\end{aligned}
$$

em que: $\mathrm{Kfs}\left(\mathrm{cm} \mathrm{s}^{-1}\right)$ é a condutividade hidráulica do solo saturado no campo, $\phi_{\mathrm{m}}\left(\mathrm{cm}^{2} \mathrm{~s}^{-1}\right)$ é o potencial matricial do fluxo, $\mathrm{Q}\left(\mathrm{cm}^{-3} \mathrm{~cm}^{-3}\right)$ é o fluxo constante, $\mathrm{H}(\mathrm{CM})$ é a carga hidráulica, $\mathrm{C}$ $(\mathrm{cm} \mathrm{cm})$ é um fator de geometria, e a $(\mathrm{cm})$ é o raio do orifício onde as medições foram feitas. A solução das equações $Q_{1}$ e $Q_{2}$ gera valores de $\mathrm{Kfs} \mathrm{em}^{-1} \mathrm{~h} \mathrm{~h}^{-1} ; \mathrm{c}$ ) A resistência à penetração do solo foi avaliada no mês de outro de 1999, nas profundidades de 0-0,10, 0,10-0,20, 0,20-0,40 m, utilizando-se um penetrômetro modelo Solotest 1.210.001.

O penetrômetro utilizado é composto de um anel dinamométrico com relógio comparador analógico, capacidade de $10 \mathrm{MPa}$ e uma ponta cônica de $6,33 \mathrm{~cm}^{2}$. O relógio comparador apresenta 0-10 mm de divisão e subdivisão de $0,01 \mathrm{~mm}$. Na aferição do equipamento a constante média do anel foi de $3,25 \mathrm{MPa} \mathrm{mm}$. Na avaliação de campo registra-se o número de divisões lidas no relógio comparador. A resistência à penetração é calculada de acordo com a curva característica do equipamento, através da equação:

$$
x=(y-a) / b \text { ou } y=a+b x
$$

em que: x é a carga aplicada (MPa), y é a leitura (número de divisões lidas no dinamômetro), a é -5,907 (para calibração do equipamento utilizado), e b é -3,186 (para a calibração do equipamento utilizado).

Os efeitos dos sistemas de uso do solo sobre a infiltração de água no solo, condutividade hidráulica do solo saturado e resistência do solo à penetração, nas diferentes profundidades estudadas, foram verificados a partir da análise de variância, seguindo-se um delineamento inteiramente casualizado, com dez repetições. A diferença entre as médias foi avaliada pelo teste de Tukey, ao nível de 5\% de probabilidade.

\section{RESULTADOS E DISCUSSÃO}

Fez-se uma análise comparativa entre as possíveis alterações nas propriedades do solo sob cultivo, em relação ao solo em seu estado natural (cerrado).

Na Tabela 1, são apresentados os dados da taxa constante de infiltração para os diferentes manejos estudados. Observase que os maiores valores corresponderam à área de cerrado $\mathrm{e}$
Tabela 1. Comparação das médias* da taxa constante de entrada de água no solo $\left(\mathrm{mm} \mathrm{h}^{-1}\right)$ em função dos tratamentos

\begin{tabular}{lc} 
Tratamento & Velocidade de Infiltração $\left(\mathrm{mm} \mathrm{h}^{-1}\right)$ \\
\hline Cerrado & $330 \mathrm{a}$ \\
Plantio direto & $228 \mathrm{~b}$ \\
Cultivo mínimo & $264 \mathrm{a}$ \\
Seringueira & $162 \mathrm{c}$ \\
Pastagem & $190 \mathrm{c}$ \\
Convencional & $221 \mathrm{~b}$ \\
$\mathrm{CV}=27,8 \%$ & \\
DMS $(5 \%)=7,78$ & \\
\hline
\end{tabular}

"Médias seguidas de mesma letra, na linha, não diferem significativamente pelo teste de Tukey, ao nivel de $5 \%$

ao cultivo mínimo, sendo que os mesmos não diferiram estatisticamente pelo teste de Tukey. Os sistemas plantio direto e convencional apresentaram valores intermediários e não diferiram estatisticamente, e o menor valor observado para este atributo correspondeu ao sistema da seringueira e pastagem, diferindo estatisticamente dos demais sistemas de manejo devido, provavelmente, ao processo de compactação, sendo que este fator tem sido citado por alguns pesquisadores (Raves \& Cooper, 1960 e Gent Jr. et al., 1984). Todos eles concordam em atribuir as modificações na distribuição das partículas do solo que provocam diminuição no tamanho dos poros, especialmente daqueles de tamanho maior (macroporos) o que produz uma redução na área da seção transversal para o fluxo de água, juntamente com percursos mais tortuosos para o movimento de fluido afetando, assim, o processo de infiltração, de acordo com os manejos utilizados. Sarvasi (1994) estudando a dinâmica da água, erosão hídrica e produtividade das culturas em função do preparo do solo, observou que o cultivo mínimo apresentou resultados satisfatórios quanto a infiltração de água no solo.

$\mathrm{Na}$ Figura 1 tem-se as infiltrações acumuladas estimadas e observadas $(\mathrm{mm})$ referentes aos sistemas de manejo estudados. A constatação de que a infiltração é maior na mata nativa que em solos cultivados foi observada nos trabalhos de (Leite \& Medina, 1984; Corrêa, 1985; Cavenage et al., 1999; Centurion et al., 2001).

A infiltração de água indica diferenças no comportamento hidrodinâmico do solo em função da alteração de sua estrutura. Considerando-se que a infiltração de água reflete as condições físicas do solo, como estrutura, porosidade e ausência de camadas compactadas, deduz-se que nos solos estudados elas sofreram modificações acentuadas em função do manejo. As maiores alterações foram encontradas no solo sob pastagem e seringueira, em função da elevada resistência do solo à penetração de água.

Os valores de condutividade hidráulica do solo saturado (Kfs) encontram-se na Tabela 2, na qual se observa que o sistema cerrado apresentou os maiores valores para o $\mathrm{Kfs}$, em todas as profundidades estudadas, diferindo estatisticamente dos demais sistemas de manejo. Os sistemas cultivo mínimo e plantio direto mostraram valores intermediários, porém, não diferiram estatisticamente pelo teste de Tukey ao nível de $5 \%$ de probabilidade, mas os sistemas seringueira, pastagem e convencional, indicaram os menores valores para a avaliação em questão, com destaque para o sistema da seringueira, que foi o menor dos três citados, nas profundidades de 0-0,10 e 0,10-0,20 m. Observa-se, também, nos sistemas de manejo com cerrado e cultivo mínimo, que a condutividade hidráulica do solo saturado diminui em profundidade, porém, nos sistemas com plantio direto, seringueira, 


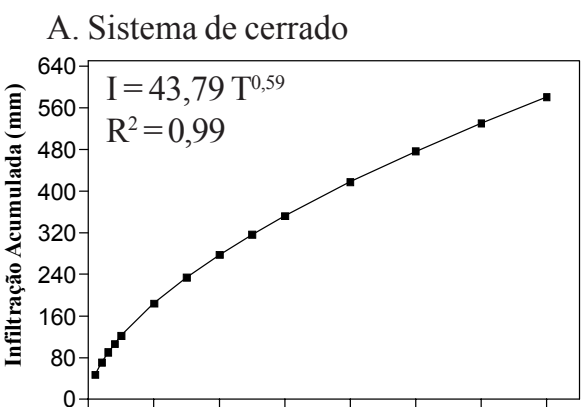

D. Sistema de seringueira

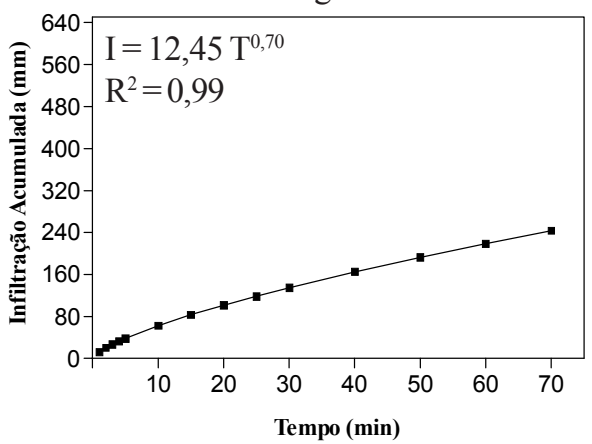

B. Sistema de cultivo mínimo

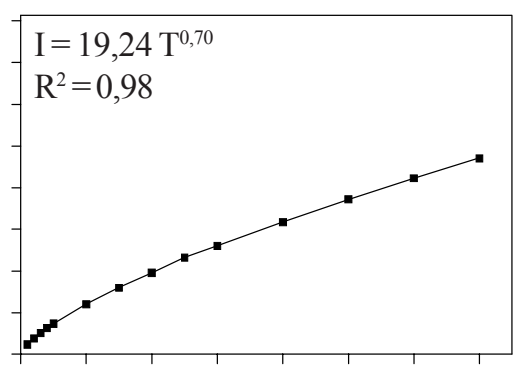

E. Sistema de pastagem

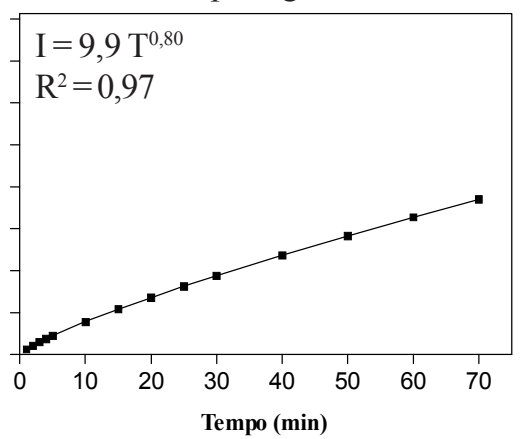

C. Sistema de plantio direto

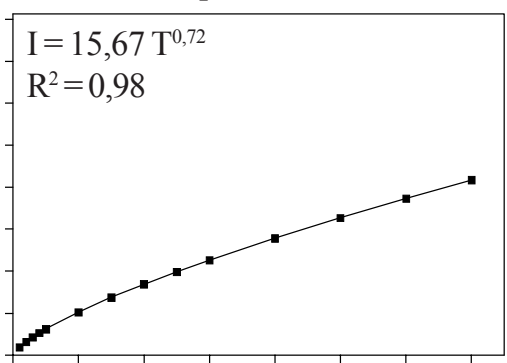

F. Sistema convencional

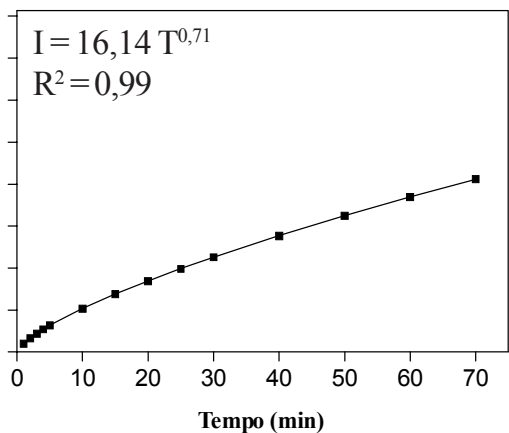

Figura 1. Infiltração acumulada, estimada e observada (mm) para tratamentos (A) sistema de cerrado; (B) sistema de cultivo mínimo;

(C) sistema de plantio direto; (D) sistema de seringueira; (E) sistema de pastagem; (F) sistema convencional

Tabela 2. Comparação das médias* da condutividade hidráulica saturada $\left(\mathrm{cm} \mathrm{h}^{-1}\right)$ e resistência à penetração $(\mathrm{MPa})$ em função dos tratamentos e das profundidades estudadas

\begin{tabular}{lccc}
\hline \multirow{2}{*}{ Tratamento } & \multicolumn{3}{c}{ Profundidade $(\mathrm{m})$} \\
\cline { 2 - 4 } & $0-0,10$ & $0,10-0,20$ & $0,20-0,40$ \\
\hline A. Condutividade hidráulica saturada $\left(\mathrm{cm} \mathrm{h}^{-1}\right)$ & \\
Cerrado & $13,42 \mathrm{Aa}$ & $9,10 \mathrm{Ab}$ & $8,21 \mathrm{Ab}$ \\
Plantio Direto & $3,66 \mathrm{Ba}$ & $4,10 \mathrm{Ba}$ & $3,62 \mathrm{Ca}$ \\
Cultivo mínimo & $5,41 \mathrm{Ba}$ & $4,48 \mathrm{Bb}$ & $5,17 \mathrm{Ba}$ \\
Seringueira & $0,81 \mathrm{Da}$ & $1,35 \mathrm{Ca}$ & $0,96 \mathrm{Da}$ \\
Pastagem & $2,29 \mathrm{Ca}$ & $1,90 \mathrm{Ca}$ & $2,27 \mathrm{Ca}$ \\
Convencional & $2,53 \mathrm{Ca}$ & $1,85 \mathrm{Ca}$ & $2,68 \mathrm{Ca}$ \\
\hline CV=59,15\% (Tratamento) & \multicolumn{1}{c}{$\mathrm{CV}=3,19 \%$ (profundidade) } \\
\hline DMS(5\%)=8,74 (Tratamento) & $\mathrm{DMS}(5 \%)=6,95$ (profundidade) \\
\hline B. Resistência à penetração (MPa) & $1,27 \mathrm{Bb}$ & $1,71 \mathrm{Ba}$ & $1,61 \mathrm{Ca}$ \\
Cerrado & $1,99 \mathrm{Ab}$ & $2,86 \mathrm{Aa}$ & $2,21 \mathrm{Bb}$ \\
Plantio Direto & $1,30 \mathrm{Bc}$ & $1,93 \mathrm{Bb}$ & $2,10 \mathrm{Ba}$ \\
Cultivo mínimo & $2,00 \mathrm{Ac}$ & $3,21 \mathrm{Aa}$ & $2,61 \mathrm{Ab}$ \\
Seringueira & $1,95 \mathrm{Ab}$ & $2,96 \mathrm{Aa}$ & $2,25 \mathrm{Bb}$ \\
Pastagem & $1,90 \mathrm{Ac}$ & $3,24 \mathrm{Aa}$ & $2,57 \mathrm{Ab}$ \\
Convencional & $\mathrm{CV}=12,8 \%$ (profundidade) \\
\hline CV=26,42\% (Tratamento) & $\mathrm{DMS}(5 \%)=0,77$ (profundidade) \\
\hline DMS(5\%)=1,37 (Tratamento) &
\end{tabular}

"Médias seguidas de mesma letra, maiúsculas nas colunas e minúsculas nas linhas, não diferem pelo teste de Tukey ao nível de $5 \%$ de probabilidade

pastagem e preparo convencional, não houve diferença entre as profundidades em relação à condutividade hidráulica.

Valores mais altos de condutividade hidráulica do solo saturado nos sistemas de plantio direto e cultivo mínimo podem ser explicados pela continuidade dos poros e pela maior atividade biológica da micro, meso e macrofauna, sendo que este fato é concordante com os resultados obtidos por Arzeno (1990); Sarvasi (1994) e Castro, (1995). Os mesmos autores, trabalhando com diferentes sistemas de preparo e com o permeâmetro de Guelph, verificaram que a condutividade hidráulica do solo saturado apresentou diferenciação no plantio direto e convencional próximo à superfície. Ressalta-se que no preparo convencional, devido à mobilização do solo, predomina a descontinuidade dos poros, enquanto no plantio direto ela apresenta um contínuo de poros que facilita a movimentação tridimensional da água; situação semelhante foi encontrada nos trabalhos em questão e o mesmo foi observado por Logsdon et al. (1990) e Khakural et al. (1992).

Foram encontrados altos valores de coeficiente de variação para a condutividade hidráulica do solo saturado. Segundo Sarvasi (1994) pode-se atribuir o efeito local aos altos coeficientes de variação proporcionando, desta forma, variações notáveis no comportamento dos sistemas estudados. Arzeno (1990), Castro (1995) e Sarvasi (1994), avaliando a condutividade hidráulica do solo saturado em diferentes sistemas de manejo, também encontraram altos valores de coeficiente de variação. Os autores mencionam que o fato se deve especialmente à alta variabilidade espacial dos solos, típico das propriedades de movimentação tridimensional da água.

Embora o revolvimento do solo possa aumentar a proporção de macroporos em relação ao plantio direto (Vieira \& Muzilli, 1984; Castro et al., 1987), sua continuidade seria interrompida, reduzindo sua eficiência na transmissão de água (Wu et al., 1992), apesar de haver relatos de maior condutividade hidráulica saturada sob preparo convencional (Corrêa, 1985; Pelegrini et al., 1990; Pierce et al., 1992).

Observa-se, na Tabela 2, que em todos os sistemas de manejo do solo houve tendência de formação de camada compactada em diferentes profundidades, medidas pelo penetrômetro de impacto. Os menores resultados obtidos nas profundidades 0 0,10 m e 0,10-0,20 m foram verificados nas áreas do cerrado e cultivo mínimo, não diferindo estatisticamente. Os sistemas de 
plantio direto, seringueira e convencional, apresentaram valores relativamente altos em todas as profundidades avaliadas, para a resistência à penetração, sendo que na área da seringueira e convencional, notaram-se valores altos nas profundidades de 0,10-0,20 e 0,20-0,40 m.

A caracterização dos efeitos relativos ao tipo de manejo da área experimental indica um pico de resistência à penetração na profundidade de 0,10-0,20 m, podendo esta compactação ser resultante do preparo do solo (convencional e seringueira) e para o sistema de pastagem, devido ao pisoteio excessivo promovido pelos animais durante o pastejo, sendo que estes resultados são concordantes com Peña et al. (1996) e Tormena \& Roloff(1996).

A formação de camada compactada a diferentes profundidades, com uso e manejo do solo, é quantificada pelos valores maiores que 2,0 MPa, limite crítico sugerido por Tormena (1998) em um Latossolo Roxo, podendo influenciar o desenvolvimento das culturas. Assim, todos os sistemas de manejo estudados induziram à formação de camadas compactadas na profundidade de 0,20-0,40 m, em níveis que possivelmente afetam o desenvolvimento radicular das culturas.

\section{CONCLUSÕES}

1. As diferentes formas de uso e manejo do solo promoveram alterações no movimento da água no solo e na resistência do solo à penetração.

2. O sistema de cultivo mínimo revelou-se como o sistema de manejo com melhores resultados, mostrando maiores valores de infiltração e condutividade hidráulica do solo saturado e menor resistência do solo à penetração, quando comparado com a vegetação natural, sendo que o sistema de plantio direto também apresentou valores similares ao sistema de vegetação natural.

3. Os sistemas de pastagem e seringueira apresentaram os menores valores de infiltração de água no solo, condutividade hidráulica do solo saturado e maior valor de resistência do solo à penetração, em relação à vegetação natural.

\section{LITERATURA CITADA}

Arshad, M.A.; Lowery, B.; Grossman, B. Physical tests for monitoring soil quality. In: Doran, J.W.; Jones, A.J. (eds.) Methods for assessing soil quality. Madison, Soil Science Society of America. 1996. p.123-141. SSSA Special publication, 49

Arzeno, J.L. Avaliação física de diferentes manejos de solo em um Latossolo Roxo - distrófico. Piracicaba: ESALQ/USP, 1990. 259p. Tese Doutorado

Bertrand, A.R. Rate of water intake in the field. In: Black, C.A. (ed.). Methods of soil analysis. Part 1. Madison: American Society of Agronomy, 1965. p.197-208.

Castro, O.M. Comportamento físico e químico de um Latossolo Roxo em função de seu preparo na cultura do milho (Zea mays L). Piracicaba: ESALQ/USP, 1995. 174p. Tese Doutorado

Castro, O.M.; Camargo, O.A.; Vieira, S.R.; Dechen, S.C.F.; Cantarella, H. Caracterização química e física de dois Latossolos em plantio direto e convencional. Campinas: Instituto Agronômico, 1987.23p. Boletim Científico, 11
Cavenage, A.; Moraes, M.L.T.; Alves, M.C.A.; Carvalho, M.A.C.; Freitas, M.L.M.; Buzetti, S. Alterações nas propriedades físicas de um Latossolo Vermelho-Escuro, sob diferentes culturas. Revista Brasileira de Ciência do Solo, Viçosa, v.23, n.4, p.997-1003, 1999.

Centurion, J.F.; Cardoso, J.P.; Natale, W. Efeito de formas de manejo em algumas propriedades físicas e químicas de uma Latossolo Vermelho em diferentes agroecossistemas. Revista Brasileira de Engenharia Agrícola e Ambiental, Campina Grande, v.5, n.2, p.254-258, 2001.

Corrêa, J.C. Características físicas de um Latossolo Amarelo muito argiloso. Pesquisa Agropecuária Brasileira, Brasília, v.20,n.11, p.1381-1387, 1985.

Correchel, V.; Silva, A.P.; Tormena, C.A. Influência da posição relativa à linha de cultivo sobre a densidade do solo em dois sistemas de manejo do solo. Revista Brasileira de Ciência do Solo, Viçosa, v.23, n.1, p.165-173, 1999.

De Maria, I.C.; Castro O.M.; Souza Dias, H. Atributos físicos do solo e crescimento radicular de soja em Latossolo Roxo sob diferentes métodos de preparo do solo. Revista Brasileira de Ciência do Solo, Viçosa, v.23, n.3, p.703-709, 1999.

Demattê, J.L.I. Levantamento detalhado dos solos do "Campus Experimental de Ilha Solteira”. Piracicaba: Escola Superior de Agricultura Luiz de Queiroz, 1980. p.11-31.

Derpsch, R.; Roth, C.; Sidiras, N.; Köpke, U. Controle de erosão no Paraná, Brasil: Sistemas de cobertura do solo, plantio direto e preparo conservacionista do solo. Eschborn: Deutsche Gesellschaff für Technische Zusammenarbeit (GTZ), 1991.272p.

Ehlers, W.; Kopke, V.; Hesse, F.; Böhm, W. Penetration resistance and root growth of oats in tilled and untilled loess soil. Soil Tillage Research, Amsterdam, v.3, n.2, p.261-275, 1983.

EMBRAPA - Empresa Brasileira de Pesquisa Agropecuária. Sistema Brasileiro de Classificação de Solos. Rio de Janeiro: Centro Nacional de Pesquisa do Solo, 1999. 412p.

Gent Jr., J.A.; Ballard, R.; Hassan, A.E.; Cassel, D.K. Impact of harvesting and site preparation on physical properties of piedmont forest soil. Soil Science of America Journal, Madison, v.48, n.1, p.173-177,1984.

Grant, C.A.; Lafond, G.P. The effects of tillage systems and crop sequences on soil bulk density and penetration resistence on a clay soil in Southern Saskatchewan. Canadian Journal Soil Science, Ottawa, v.73, n.2, p.223-232, 1993.

Khakural, B.R.; Lemme, G.D.; Schumacher, T.E.; Lindstrom, M.J. Effects of tillage and landscape on soil. Soil Tillage Research, Amsterdam, v.25, n.1, p.43-52, 1992.

Klein, V.A.; Libardi, P.L.; Silva, A.P. Resistência mecânica do solo à penetração sob diferentes condições de densidade $\mathrm{e}$ teor de água. Engenharia Agrícola, Jaboticabal, v.18, n.2, p.45-54, 1998.

Kostiakov, A.N. On the dynamics of the coefficient of waterpercolation in soils and on the necessity for studying it from a dynamic point of view purposes of amelioration. Transactions Communication 6th International Society Soil Science, Part. A, p.17-21, 1932. 
Lal, R. Role of mulching techniques in tropical soil and water management. Ibadan: International Institute of Tropical Agriculture, 1974. 37p. Technical Bulletin, 1

Leite, J.A.; Medina, F.B. Efeito dos sistemas de manejo sobre as propriedades físicas de um Latossolo Amarelo do Amazonas. Pesquisa Agropecuária Brasileira, Brasília, v.19, n.11, p.1417$1422,1984$.

Logsdon, S.D.; Allmaras, R.R.; Wu, L.; Swan, J.B.; Randall, G.W. Macroporosity and its relation to saturated hydraulic conductivity under different tillage practices. Soil Science Society of America Journal, Madison, v.54, n.4, p.1096-1101, 1990.

Pelegrini, F.; Moreno, F.; Martin-Aranda, J.; Camps, M. The influence of tillage methods is soil physical properties and water balance for a typical crop rotation SW Spain. Soil Tillage Research, Amsterdam, v.16, n.2, p.345-358, 1990.

Peña, Y.A.; Gomes, A.S.; Souza, R. O. Influência de diferentes sistemas de cultivo nas propriedades físicas de um solo de várzea cultivado com arroz irrigado. Revista Brasileira de Ciência do Solo, Campinas, v.20, n.3, p.517-523, 1996.

Pierce, F.J.; Fortin, M.C.; Staton, M.J. Immediate and residual effects of zone-tillage in rotation with no-tillage on soil physical properties and corn performance. Soil Tillage Research, Amsterdam, v.24, n.1, p.149-165, 1992.

Raves, P.R.; Cooper, R.L. Análise de redistribuição de água visando à condutividade hidráulica do solo. Energia Nuclear e Agricultura, Piracicaba, v.1, n.1, p.108-122,1960.

Reynolds, W.D.; Elrick, D.E. In situ measurement of fieldsaturated hydraulic conductivity, sorptivity, and the $\alpha$ parameters using the Guelph permeameter. Soil Science, Baltimore, v.140, n.4, p.292-302, 1985.
Sarvasi, F.O.C. Dinâmica da água, erosão hídrica e produtividade das culturas em função do preparo do solo. Piracicaba: ESALQ/USP, 1994. 161p. Dissertação Mestrado

Silveira, P.M.; Silva, J.G.; Stone, L.F.; Zimmermann, F.J.P. Efeito de sistema de preparo na densidade do solo. In: Congresso Brasileiro de Ciência do Solo, 26, 1997, Rio de Janeiro. Resumos... Rio de Janeiro: SBCS, 1997. CD Rom

Tavares Filho, J.; Tessier, D. Influence des pratiques culturales sur le comportement et les propriétés de sols du Paraná (Brésil). Étude Gestion Sols, Paris, v.5, n.1, p.61-71, 1998.

Tormena, C.A. Caracterização e avaliação do intervalo hídrico ótimo de um Latossolo Roxo. Piracicaba: ESALQ/USP, 1998. 106p. Tese Doutorado

Tormena, C.A.; Roloff, G. Dinâmica da resistência à penetração de um solo sob plantio direto. Revista Brasileira de Ciência do Solo, Campinas, v.20, n. 2, p.333-339, 1996.

Vieira, M.J.; Muzilli, O. Características físicas de um Latossolo Vermelho-Escuro sob diferentes sistemas de manejo. Pesquisa Agropecuária Brasileira, Brasília,v.19, n.7, p.873-882, 1984.

Vieira, S. R. Permeâmetro: novo aliado na avaliação de manejo do solo. O Agronômico, Campinas, v.48, p.32-33, 1996.

Vieira, S.R., Reynolds, W.D., Topp, G.C. Spatial variability of hydraulic properties in a highly structured clay soil. In: Wieranga, P. J., Bachelet, D., (ed.) Validation of flow and transport models for the unsaturated zone. Las Cruces: Department of Agronomy and Horticulture, New Mexico State University, 1988. p.471-483. Research Report 88-SS-04

Wu, L.; Swan, J.B.; Paulson, W.H.; Randall, G.W. Tillage effects on measured soil hydraulic properties. Soil Tillage Research., Amsterdam, v.25, p.17-33, 1992. 